NTP RR 10

AUGUST 2019 


\title{
NTP Research Report on Respiratory Tract Toxicity of the Flavoring Agent 2,3-Hexanedione in Mice Exposed by Inhalation
}

Research Report 10

August 2019

\author{
National Toxicology Program \\ Public Health Service \\ U.S. Department of Health and Human Services
}

ISSN: 2473-4756

Research Triangle Park, North Carolina, USA 


\section{Table of Contents}

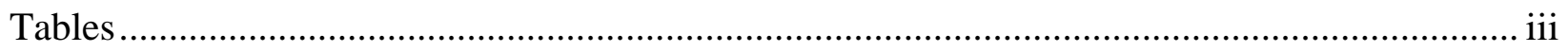

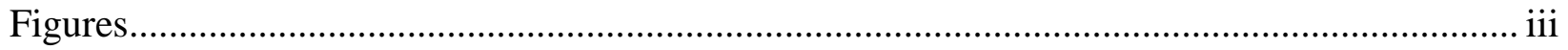

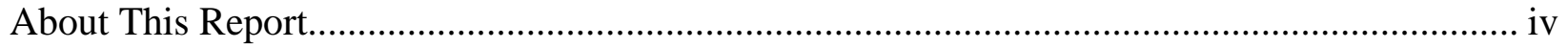

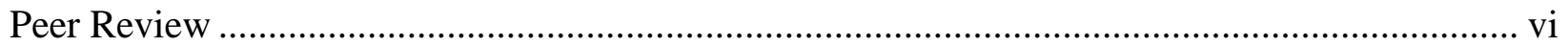

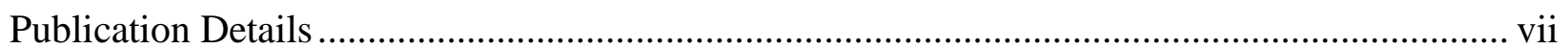

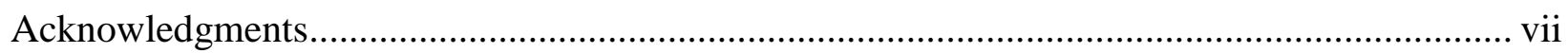

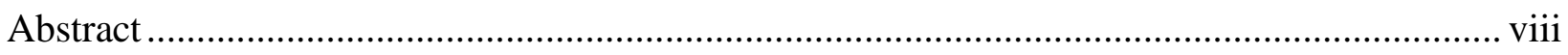

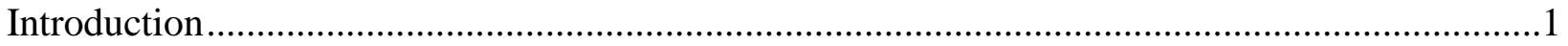

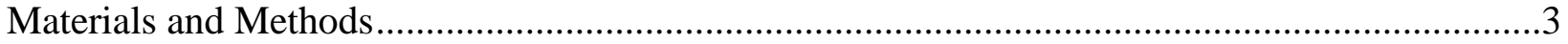

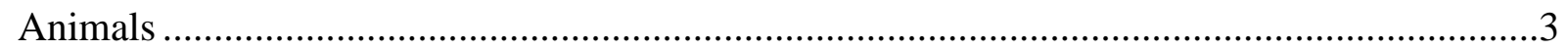

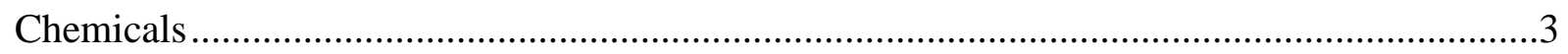

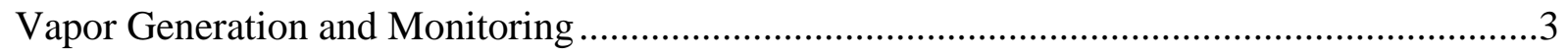

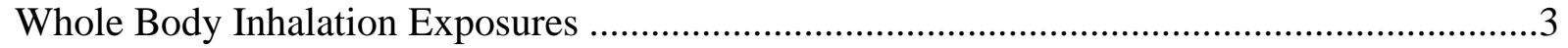

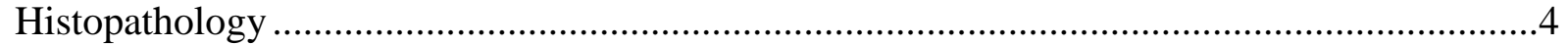

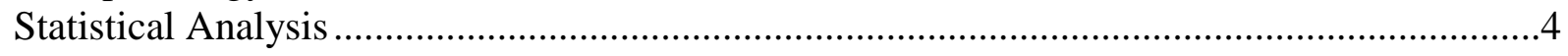

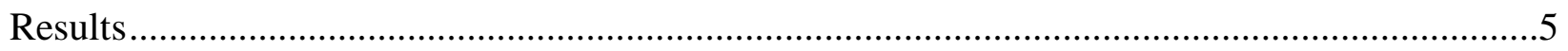

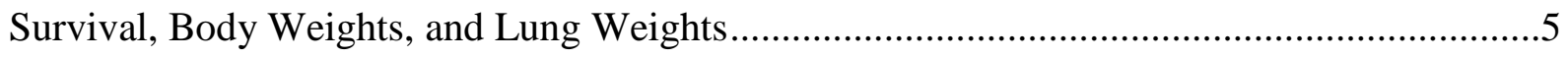

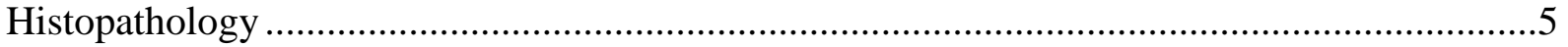

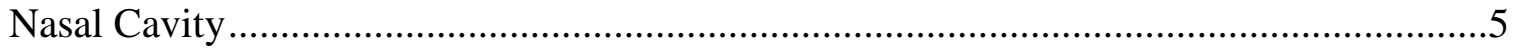

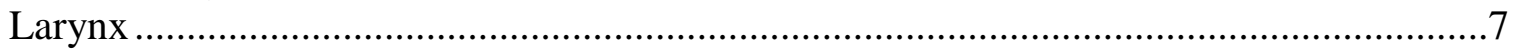

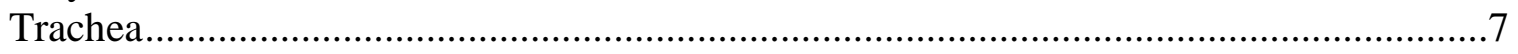

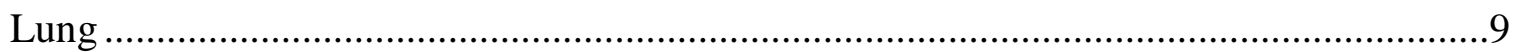

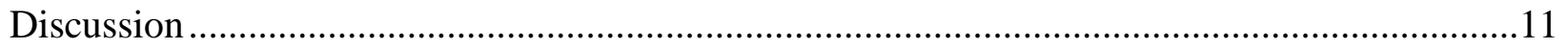

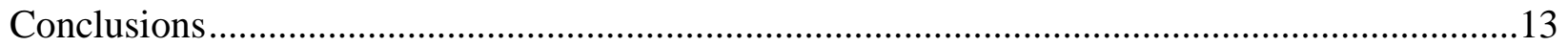

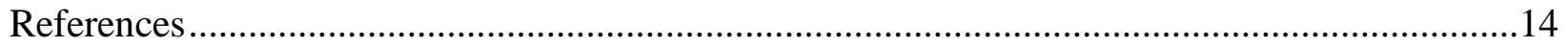




\section{Tables}

Table 1. Effects of 2,3-Hexanedione Exposure on Body and Lung Weights of Mice .....................5

Table 2. Nasal Cavity Lesions in Mice Exposed to 2,3-Hexanedione................................................6

Table 3. Laryngeal and Tracheal Lesions in Mice Exposed to 2,3-Hexanedione .............................

Table 4. Bronchial Lesions in Mice Exposed to 2,3-Hexanedione..................................................

\section{Figures}

Figure 1. Nose: Respiratory Epithelial Lesions .....................................................................

Figure 2. Nose: Turbinate and Olfactory Epithelial Lesions .........................................................17

Figure 3. Nasopharyngeal Duct: Squamous Metaplasia .............................................................18

Figure 4. Larynx: Squamous Metaplasia and Squamous Hyperplasia ..........................................19

Figure 5. Trachea: Squamous Metaplasia, Degeneration, and Ulceration......................................20

Figure 6. Lung, Bronchus: Respiratory Epithelial Lesions........................................................21 


\title{
About This Report
}

\author{
Authors \\ Daniel L. Morgan ${ }^{1}$, Gordon P. Flake ${ }^{1}$, William M. Gwinn ${ }^{1}$, Crystal L. Johnson ${ }^{2}$ \\ ${ }^{1}$ Division of the National Toxicology Program, National Institute of Environmental Health \\ Sciences, Research Triangle Park, North Carolina, USA \\ ${ }^{2}$ Charles River Laboratories, Research Triangle Park, North Carolina, USA \\ Division of the National Toxicology Program, National Institute of Environmental Health \\ Sciences, Research Triangle Park, North Carolina, USA \\ Daniel L. Morgan, Ph.D. \\ Gordon P. Flake, M.D. \\ William M. Gwinn, Ph.D. \\ Charles River Laboratories, Raleigh, North Carolina, USA \\ Crystal L. Johnson, D.V.M., DACVP
}

\section{Contributors}

Division of the National Toxicology Program, National Institute of Environmental Health Sciences, Research Triangle Park, North Carolina, USA

NTP pathology review

David E. Malarkey, D.V.M., Ph.D.

Technical assistance

Cassandra J. Shines, M.S.

Peer-review oversight

Mary S. Wolfe, Ph.D.

Alion Science and Technology Corporation, Durham, North Carolina, USA

Study conduct

Robert O'Connor, M.S.

Herman C. Price, B.S.

Integrated Laboratory Systems Inc., Research Triangle Park, North Carolina, USA

NTP pathology review

Kyathanahalli Janardhan, M.V.Sc., Ph.D.

Cynthia Willson, D.V.M., Ph.D.

ICF, Durham, North Carolina, USA

Contract oversight

Dave Burch, M.E.M. 
Respiratory Tract Toxicity of the Flavoring Agent 2,3-Hexanedione in Mice Exposed by Inhalation

Technical editing and document production, peer-review support

Susan Blaine, B.A

Natalie Blanton, M.P.H.

Canden Byrd, B.S.

Tyler Cromer, M.P.S.

Tara Hamilton, M.S.

Penelope Kellar, M.S. 
Respiratory Tract Toxicity of the Flavoring Agent 2,3-Hexanedione in Mice Exposed by Inhalation

\section{Peer Review}

The draft NTP Research Report on Respiratory Tract Toxicity of the Flavoring Agent 2,3-Hexanedione in Mice Exposed by Inhalation was evaluated by the reviewers listed below. These reviewers served as independent scientists, not as representatives of any institution, company, or governmental agency. In this capacity, reviewers determined if the design and conditions of these NTP studies were appropriate and ensured this NTP Research Report presented the experimental results and conclusions fully and clearly.

\section{Peer Reviewers}

\section{Kathy Hughes, B.S.}

Senior Program Advisor, Existing Substances Risk Assessment Bureau

Health Canada

Ottawa, Canada

Madhuri Singal, Ph.D., RRT, DABT

Manager, Inhalation Toxicology; Safety, Quality, Regulatory and Compliance Division Reckitt Benckiser

Montvale, New Jersey, USA 


\section{Publication Details}

Publisher: National Toxicology Program

Publishing Location: Research Triangle Park, NC

ISSN: $2473-4756$

DOI: https://doi.org/10.22427/NTP-RR-10

Report Series: NTP Research Report Series

Report Series Number: 10

Official citation: Morgan DL, Flake GP, Gwinn WM, Johnson CL. 2019. NTP research report on respiratory tract toxicity of the flavoring agent 2,3 -hexanedione in mice exposed by inhalation. Research Triangle Park, NC: National Toxicology Program. Research Report 10.

\section{Acknowledgments}

This research was supported by the NIH National Institute of Environmental Health Sciences. These studies were conducted at the NIEHS Inhalation Facility under contract to Alion Science and Technology, Inc. (HHSN291200775561C). 
Respiratory Tract Toxicity of the Flavoring Agent 2,3-Hexanedione in Mice Exposed by Inhalation

\begin{abstract}
2,3-Hexanedione is a 6-carbon $\alpha$-diketone flavoring agent that is a potential replacement for 2,3-butanedione. 2,3-Butanedione inhalation has been associated with obliterative bronchiolitis in workers. The inhalation toxicity data for 2,3-hexanedione are limited to one study conducted in rats. In this study, we provide additional data on the respiratory toxicity of 2,3-hexanedione in male and female B6C3F1 mice. Mice (six per group) were exposed (whole body) to 0, 100, 150, or 200 ppm 2,3-hexanedione 6 hours/day, 5 days/week for 2 weeks plus 2 days (12 exposure days total). Animals were euthanized the morning after the last exposure and respiratory tract tissues collected for histopathological evaluation. All mice survived to the end of the study. Body weights of female mice exposed to 150 and $200 \mathrm{ppm}$ 2,3-hexanedione were significantly less than controls, and relative lung weights were significantly greater following exposure to 100, 150, and $200 \mathrm{ppm}$. Squamous metaplasia was the most prevalent lesion observed in the nasal cavity, larynx, and trachea of exposed male and female mice. 2,3-Hexanedione caused atypical hyperplasia of the bronchial respiratory epithelium in male and female mice exposed to $200 \mathrm{ppm}$ 2,3-hexanedione. 2,3-Hexanedione exposure did not cause airway fibrosis or obliterative bronchiolitis in mice.
\end{abstract}

Keywords: 2,3-hexanedione (acetyl butyryl), respiratory tract, toxicity, mice, inhalation 
Respiratory Tract Toxicity of the Flavoring Agent 2,3-Hexanedione in Mice Exposed by Inhalation

\section{Introduction}

2,3-Hexanedione (acetyl butyryl) is a 6-carbon $\alpha$-diketone with a creamy, caramel-like, fruity, toasted-brown organoleptic profile ${ }^{1}$. 2,3-Hexanedione occurs naturally in coffee and beer and is used as an artificial flavoring and fragrance agent. Although 2,3-hexanedione is considered safe for consumption in foods and drinks, limited toxicity data are available for inhalation exposure to 2,3-hexanedione vapors. Non-occupational inhalation exposure to 2,3-hexanedione vapors can occur from the use of electronic cigarette liquids ${ }^{2 ; 3}$ and hookah pipes using flavored tobacco ${ }^{4 ; 5}$. Occupational exposure can occur in settings where artificial flavorings containing 2,3-hexanedione are heated or mixed without proper ventilation or use of personal protection equipment ${ }^{6 ;}$.

Concerns about the potential inhalation toxicity of 2,3-hexanedione arose from the finding that occupational exposure to 2,3-butanedione (diacetyl), a structurally related, 4-carbon $\alpha$-diketone, was associated with an increased prevalence of obliterative bronchiolitis, an irreversible and often fatal lung disease. Obliterative bronchiolitis is characterized by fibroproliferative lesions in the walls of the small airways leading to obliteration of the airway lumen and debilitating loss of lung function ${ }^{6}$. Inhalation studies in rats demonstrated that 2,3-butanedione causes obliterative bronchiolitis-like lesions ${ }^{8}$, providing additional support for the association between 2,3-butanedione exposure and obliterative bronchiolitis in workers. 2,3-Pentanedione, a 5-carbon $\alpha$-diketone has been used to replace 2,3-butanedione in some food products ${ }^{9}$; however, recent studies demonstrated that inhalation of 2,3-pentanedione vapors also causes obliterative bronchiolitis-like lesions in rats ${ }^{10}$. 2,3-Hexanedione could be used in formulating a substitute for 2,3-butanedione in the food and flavoring industries because it is less reactive ${ }^{10}$ and has organoleptic properties similar to those of 2,3-butanedione. The $\alpha$-diketone structure of 2,3-hexanedione, however, suggests that it could cause respiratory tract toxicity by the same mechanism as 2,3-butanedione and 2,3-pentanedione. In addition, because 2,3-hexanedione is less water soluble and less reactive than 2,3-butanedione, concern arose that 2,3-hexanedione might penetrate to more distal regions of the respiratory tract and cause greater toxicity in the deeper lung. Although estimated production of 2,3-hexanedione is considerably lower than that for 2,3-butanedione and 2,3-pentanedione ${ }^{11 ; 12}$, its use as a replacement for 2,3-butanedione and 2,3-pentanedione could result in greater production and thus greater potential for worker exposure.

Inhalation toxicity data for 2,3-hexanedione are currently limited to one study conducted in male Wistar Han rats ${ }^{10}$. The study compared the reactivity and respiratory tract toxicity of 2,3-hexanedione with that of 2,3-butanedione and 2,3-pentanedione. 2,3-Hexanedione was found less reactive and less toxic for the respiratory tract of rats than 2,3-butanedione or 2,3-pentanedione, and did not cause obliterative bronchiolitis or deficits in pulmonary function. Like 2,3-butanedione and 2,3-pentanedione, however, 2,3-hexanedione inhalation caused injury to the upper respiratory tract in rats. Squamous metaplasia and hyperplasia of the respiratory epithelium and atrophy of the olfactory epithelium in the nasal cavities of rats increased when exposed to 100, 150, and 200 ppm 2,3-hexanedione for 2 weeks. Exposure to $200 \mathrm{ppm}$ 2,3-hexanedione for 2 weeks also caused hyperplasia in the bronchial and bronchiolar epithelia in most animals and minimal, focal bronchial fibrosis in two rats. 
The inhalation toxicity of 2,3-hexanedione vapors has not been studied in mice. 2,3-Butanedione and 2,3-pentanedione have been reported to cause respiratory tract toxicity in mice following inhalation exposure; however, unlike rats, exposed mice did not develop obliterative bronchiolitis $^{8 ; 13}$. Lesions in C57BL/6 mice exposed to $100 \mathrm{ppm}$ 2,3-butanedione for 12 weeks included necrosis, ulceration, and squamous metaplasia of the respiratory epithelium in the nose, bronchial epithelial atrophy and denudation, and peribronchial and peribronchiolar lymphocytic inflammation in the lungs ${ }^{13}$. Exposure of B6C3F1 mice to $200 \mathrm{ppm}$ 2,3-pentanedione for 2 weeks caused similar lesions to the epithelium lining the nasal cavity, larynx, and airways (unpublished data).

Currently no occupational exposure limits for 2,3-hexanedione vapor have been established. 2,3-Hexanedione is less reactive and less toxic than 2,3-butanedione or 2,3-pentanedione in rats ${ }^{10}$ and might be considered in formulating a replacement for these toxic diketones, but additional inhalation toxicity data are needed. The objective of this study was to characterize the potential toxicity of inhaled 2,3-hexanedione vapor in mice and to provide concentration-response data in a second rodent species. These data are needed to help establish whether 2,3-hexanedione could be a substitute for 2,3-butanedione and to help set exposure limits to protect workers. 


\section{Materials and Methods}

\section{Animals}

Male and female B6C3F1 mice (6-7 weeks old) were obtained from Charles River Laboratories (Raleigh, NC). Animals were individually housed in polycarbonate cages for 7-10 days after arrival and were provided with food (NIH-31) and water ad libitum. Animals were housed in a humidity- and temperature-controlled, HEPA (high efficiency particulate air)-filtered, mass air displacement room with a light-dark cycle of 12 hours (light from 7:00 a.m. to 7:00 p.m.) in facilities accredited by the American Association for Accreditation of Laboratory Animal Care. Animals were acclimated to the inhalation exposure conditions by placing them in wire exposure batteries in the Hazleton 1000 chambers for 3 days prior to exposure. This study was conducted under federal guidelines for the care and use of laboratory animals and was approved by the Alion Science and Technology Animal Care and Use Committee.

\section{Chemicals}

2,3-Hexanedione (CAS\# 3848-24-6) was purchased from Penta Manufacturing Co. (Livingston, NJ). 2,3-Hexanedione (98.1\%) is a clear yellow liquid with a strong butter-like odor.

\section{Vapor Generation and Monitoring}

The vapor generation system for 2,3-hexanedione consisted of a metering pump (Fluid Metering, Inc., Syosset, NY) and a heated vaporization flask. Bulk chemical was metered into a flatbottomed vaporization flask mounted on top of a stirring hot plate. The hot plate was maintained at approximately $150^{\circ} \mathrm{C}$ to ensure the chemical flashed quickly. Using compressed breathing air, the vapor was swept from the flask and into the process air stream where it was further diluted before entering the exposure chamber. The concentration in each chamber was monitored in real time using dedicated Fourier transform infrared spectrophotometers (Hamilton Sunstrand, Pomona, CA). Data from each spectrophotometer were used in a computerized feedback control system to adjust the speed of each metering pump, thus maintaining a constant concentration in each chamber. The chamber air was maintained at $24^{\circ} \pm 3^{\circ} \mathrm{C}$ and $40-70 \%$ relative humidity. Chamber air samples were analyzed for the presence of aerosols using an aerosol monitor (model 1055 PPM, Inc., Knoxville, TN). Aerosol levels at all exposure concentrations were not significantly different from conditioned air without 2,3-hexanedione.

\section{Whole Body Inhalation Exposures}

Animals (6/sex/concentration) were exposed to nominal concentrations of $0,100,150$, or 200 ppm 2,3-hexanedione in Hazleton 1000 whole body exposure chambers, 6 hours/day, 5 days/week (Monday through Friday) for 2 weeks plus 2 consecutive days prior to sacrifice (12 days of exposure total). Control mice were exposed to filtered, conditioned air at the same flow rate in the control chamber. Mean daily exposure concentrations were within $\pm 5 \%$ of target concentrations throughout the study. Food was removed during exposures and water was always available. The animals remained in the chambers for the duration of the study. Animals were evaluated for respiratory difficulties or other signs of moribundity before and after each exposure and on weekends. 


\section{Histopathology}

All animals were euthanized (Nembutal, thoracotomy) on the morning following the last exposure. The nasal cavity, lung, trachea, and larynx were collected. Lungs were weighed and inflated with $10 \%$ neutral-buffered formalin (NBF) to a normal inspiratory volume, then the trachea was ligated and the lungs immersed in NBF. After fixation in NBF for 24 hours, tissues were transferred to $70 \%$ ethanol and refrigerated until processed. The nasal cavities were fixed by retrograde infusion of NBF, followed by immersion in NBF. The formalin-fixed nasal cavities were decalcified (RDO Rapid Decalcifier, Apex Engineering Products, Aurora, IL) for 5 hours and then sectioned at three levels. Proceeding from anterior to posterior, Level I was taken immediately posterior to the upper incisor teeth; Level II was taken through the level of the incisive papilla anterior to the first palatal ridge; and Level III was taken through the middle of the second molar teeth. Fixed tissues were routinely processed, embedded in paraffin, sectioned, and mounted on slides. Slides were stained with hematoxylin and eosin (H\&E) and evaluated by light microscopy.

Histopathologic assessment by light microscopy was quantified by recording the number of animals with each lesion and the total number of animals evaluated. Average severity grades were assigned for animals with lesions in nose, larynx, trachea, bronchi, and lung, and the severity was graded as: minimal $=1$, mild $=2$, moderate $=3$, marked $=4$. Total group scores were calculated by multiplying the number of animals with each lesion by the average severity grade for that lesion, and then adding the products obtained for each of these lesions.

All slides from all mice in each dose group were originally evaluated by a study pathologist (CLJ), and all slides from all mice in each dose group were subsequently reevaluated by a quality assurance pathologist (GPF). Representative slides showing the lesions agreed upon by the study pathologist and the quality assurance pathologist and any discrepancies between the two pathologists then were reviewed by three additional pathologists (DEM, CW, KJ) in a pathology peer review. The final diagnoses in the study represent the consensus opinion of the pathology peer-review group and the quality assurance pathologist.

\section{Statistical Analysis}

Statistically significant exposure-related changes in organ weights were evaluated by two-tailed unpaired t-tests, and statistically significant incidences of exposure-related histopathological lesions were determined by a one-tailed Fisher's exact test (PrismGraphPad 7). 


\section{Results}

\section{Survival, Body Weights, and Lung Weights}

All male and female mice survived to the end of the study. Body weights of female mice exposed to 150 and 200 ppm 2,3-hexanedione for 2 weeks were significantly less than controls (Table 1). Lung weights of female mice were significantly increased following exposure to $100 \mathrm{ppm}$ (absolute and relative weights) and $150 \mathrm{ppm}$ and $200 \mathrm{ppm}$ (relative weights).

Table 1. Effects of 2,3-Hexanedione Exposure on Body and Lung Weights of Mice

\begin{tabular}{lcccc}
\hline & $\mathbf{0 ~} \mathbf{~ p m}$ & $\mathbf{1 0 0} \mathbf{~ p p m}$ & $\mathbf{1 5 0} \mathbf{~ p p m}$ & $\mathbf{2 0 0} \mathbf{~ p p m}$ \\
\hline Male Mice & & & \\
\hline Body Wt (g) & $26.3 \pm 3.2$ & $26.5 \pm 0.7$ & $25.4 \pm 0.9$ & $24.7 \pm 1.5$ \\
Lung Wt (g) & $0.172 \pm 0.018$ & $0.197 \pm 0.024$ & $0.190 \pm 0.032$ & $0.176 \pm 0.015$ \\
Lung Wt (\%) & $0.668 \pm 0.140$ & $0.745 \pm 0.089$ & $0.746 \pm 0.100$ & $0.714 \pm 0.073$ \\
\hline Female Mice & & & \\
\hline Body Wt (g) & $24.1 \pm 0.5$ & $23.3 \pm 1.0$ & $21.5 \pm 0.7^{* * *}$ & $21.0 \pm 1.0^{* * *}$ \\
Lung Wt (g) & $0.156 \pm 0.012$ & $0.183 \pm 0.013^{*}$ & $0.177 \pm 0.029$ & $0.167 \pm 0.011$ \\
Lung Wt (\%) & $0.649 \pm 0.043$ & $0.787 \pm 0.053^{*}$ & $0.824 \pm 0.154^{* * *}$ & $0.797 \pm 0.060^{*}$ \\
\hline
\end{tabular}

Mice were exposed to 2,3-hexanedione vapor 6 hours/day, 5 days/week for 2 weeks. Significant exposure-related changes in body and lung weights were observed only in female mice.

Relative lung weight $(\%)=$ lung wt $(\mathrm{g}) /$ body wt $(\mathrm{g}) \times 100$.

Values represent means $\pm \mathrm{SD}, \mathrm{n}=6$ mice/group; $* \mathrm{p}<0.05, * * \mathrm{p}<0.01 ; * * * \mathrm{p}<0.001$

\section{Histopathology}

\section{Nasal Cavity}

Many lesions were present with increased incidence in the nasal cavity of exposed mice when compared with air-exposed controls (Table 2). Suppurative exudate and chronic/active inflammation were present in the nasal cavity of all male and female mice exposed to 150 and $200 \mathrm{ppm}$ 2,3-hexanedione and in most of those exposed to $100 \mathrm{ppm}$. The lesions were primarily minimal to mild in severity. Microscopically, suppurative exudate was characterized by clusters of neutrophils within the nasal lumen, often with proteinaceous precipitate and sometimes mixed with cellular debris (Figure 1B). Chronic/active inflammation of the nasal mucosa presented as scattered infiltrates of neutrophils, lymphocytes, and macrophages within the lamina propria, with neutrophils sometimes transmigrating the epithelium in these areas (Figure 1C). Small foci of necrosis of the nasal respiratory epithelium were present in some exposed mice (Figure 1D), often at the tips of nasoturbinates and maxilloturbinates; most lesions were minimal in severity and more prevalent in exposed female mice $(68 \%)$ than in males $(17 \%)$. Necrosis was typified by eosinophilic epithelium with pyknotic nuclei that was sometimes detached from the underlying mucosa and associated with neutrophilic infiltrate and fibrin deposition. Regeneration of the respiratory epithelium was present in most of the 150 and 200 ppm exposed mice in Levels I and II (Figure 1E). Squamous metaplasia was observed in all exposed mice (Figure 1F). These two 
lesions were often adjacent, with zones of regenerative epithelium transitioning into squamous metaplasia with a flattened layer at the surface.

Table 2. Nasal Cavity Lesions in Mice Exposed to 2,3-Hexanedione

\begin{tabular}{|c|c|c|c|c|}
\hline & 0 ppm & 100 ppm & 150 ppm & $200 \mathrm{ppm}$ \\
\hline \multicolumn{5}{|l|}{ Male Mice } \\
\hline Suppurative exudate & 0 & $4^{\mathrm{a}}(1.5)^{\mathrm{b}}$ & $6^{* *}(2.0)$ & $6 * *(1.8)$ \\
\hline Chronic active inflammation & 0 & $6^{* *}(1.2)$ & $6^{* *}(1.3)$ & $6 * *(1.0)$ \\
\hline \multicolumn{5}{|l|}{ Respiratory epithelium } \\
\hline Necrosis & 0 & 0 & $1(1.0)$ & $2(1.0)$ \\
\hline Metaplasia, squamous & 0 & $6 * *(2.0)$ & $6 * *(2.7)$ & $6^{* *}(2.5)$ \\
\hline Regeneration & 0 & 0 & $5^{*}(1.2)$ & $6^{* *}(2.3)$ \\
\hline Turbinate, atrophy & 0 & $2(1.5)$ & $6^{* *}(1.5)$ & $6 * *(1.0)$ \\
\hline Turbinate, necrosis & 0 & $2(1.0)$ & $2(1.0)$ & $3(1.0)$ \\
\hline Olfactory epithelium, atrophy & 0 & $4(1.3)$ & $6 * *(1.7)$ & $6 * *(2.0)$ \\
\hline \multicolumn{5}{|l|}{ Nasopharyngeal duct } \\
\hline Suppurative exudate & 0 & $2(1.0)$ & $3(1.0)$ & $1(1.0)$ \\
\hline Metaplasia, squamous & 0 & 0 & $1(1.0)$ & $5(1.0)^{*}$ \\
\hline \multicolumn{5}{|l|}{ Female Mice } \\
\hline Suppurative exudate & 0 & $5 *(1.2)$ & $7 * *(1.9)^{\mathrm{c}}$ & $6 * *(1.8)$ \\
\hline Chronic active inflammation & 0 & $5^{*}(1.2)$ & $7 * *(1.1)^{\mathrm{c}}$ & $6 * *(1.0)$ \\
\hline \multicolumn{5}{|l|}{ Respiratory epithelium } \\
\hline Necrosis & 0 & $3(1.0)$ & $4(1.3)^{\mathrm{c}}$ & $6 * *(1.0)$ \\
\hline Metaplasia, squamous & 0 & $6^{* *}(2.0)$ & $7 * *(2.3)^{\mathrm{c}}$ & $6 * *(3.0)$ \\
\hline Regeneration & 0 & 0 & $3(1.0)^{\mathrm{c}}$ & $5 *(1.2)$ \\
\hline Turbinate, atrophy & 0 & 0 & $4(1.0)^{\mathrm{c}}$ & $3(1.7)$ \\
\hline Turbinate, necrosis & 0 & & $2(1.0)^{\mathrm{c}}$ & $3(2.0)$ \\
\hline Olfactory epithelium, atrophy & 0 & $2(1.0)$ & $5^{*}(1.4)^{\mathrm{c}}$ & $6 * *(1.5)$ \\
\hline \multicolumn{5}{|l|}{ Nasopharyngeal duct } \\
\hline Suppurative exudate & 0 & $3(1.0)$ & $1(3.0)^{\mathrm{c}}$ & $2(1.0)$ \\
\hline Metaplasia, squamous & 0 & $1(1.0)$ & $2(1.5)^{\mathrm{c}}$ & $6^{* *}(1.5)$ \\
\hline
\end{tabular}

Mice were exposed to 2,3-hexanedione vapor 6 hours/day, 5 days/week for 2 weeks.

$* \mathrm{p}<0.05, * * \mathrm{p}<0.01$ significantly increased incidences relative to controls.

${ }^{a}$ Number of mice with lesion ( $\mathrm{n}=6$ per group).

${ }^{\mathrm{b}}$ Average severity grade $(1=$ minimal, $2=$ mild, $3=$ moderate, $4=$ marked $)$.

${ }^{c} n=7$ mice per group.

The most prominent regenerative changes were noted in the ventral meatus epithelium of Level II in the 200 ppm groups, primarily along the lateral wall. Squamous metaplasia was characterized by regionally extensive areas where the normal respiratory epithelium was replaced by a variably thickened layer of stratified squamous epithelium that sometimes 
progressed to keratinization along the superficial surface. Squamous metaplasia was typically observed in Level I and was present along the turbinates, lateral walls of the nasal lumen, and occasionally along the septum.

Minimal turbinate necrosis, usually presenting as small fragments of extruded or partially extruded necrotic bone in the nasal lumen, occurred at the tips of turbinates in Level I of a few male and female mice (Figure 2A, B). Nasal turbinate atrophy, minimal to mild, was noted primarily in the 150 and 200 ppm groups and was characterized by slight shortening and blunting of the nasoturbinates and maxilloturbinates (Figure 2C, D). In addition, the ethmoid turbinates of Level III often appeared mildly reduced in length and width, in association with proteinaceous exudate partially filling the lumen (Figure 2E, F).

Olfactory epithelial atrophy, usually minimal to mild, was noted in Level III of all $200 \mathrm{ppm}$ mice, most of the $150 \mathrm{ppm}$ animals, and some of the $100 \mathrm{ppm}$ groups (Figure 2E, F). The atrophy was characterized by a reduction in the thickness and number of nuclear layers of the olfactory epithelium lining the ethmoid turbinates and was usually accompanied by proteinaceous precipitate filling the lumen of Level III. Because olfactory epithelial atrophy was not observed in the dorsal meatus of Level II, the olfactory epithelial atrophy in Level III could be associated with a pressure effect resulting from the proteinaceous material filling the nasal lumen in Level III.

The nasopharyngeal duct was assessed separately and contained similar but fewer lesions than the nose (Table 2). Lesions observed within the nasopharyngeal duct included squamous metaplasia (Figure 3) of the respiratory epithelium, epithelial regeneration, and suppurative exudate present in the lumen of the duct. The incidence of squamous metaplasia increased with increasing exposure concentration.

No findings were present in the nasal cavity or nasopharyngeal duct of control animals.

\section{Larynx}

A variety of lesions were present in the larynx of exposed mice (Table 3). Squamous metaplasia was present in all exposed male mice and almost all female mice (Figure 4A, B), and was associated with mild chronic active inflammation. The squamous metaplastic epithelium replaced the normal respiratory epithelium of the base of the epiglottis (Grade 1), extended to the lateral walls of the larynx in Level I (Grade 2), often extended into Level II (Grade 3), and sometimes was extensive in all sections (Grade 4). Hyperplasia of the squamous epithelium lining the arytenoid cartilage (Figure 4C, D) and hyperplasia of the respiratory epithelium were noted in some males and females, in conjunction with the squamous metaplasia. Vacuolar cytoplasmic degenerative change, usually of a minimal-to-mild degree, was observed in focal areas of the respiratory epithelium of some animals.

\section{Trachea}

The epithelium of almost all exposed mice exhibited alterations that included karyomegaly, degenerative changes, and variation in thickness from low cuboidal epithelium to multilayered hyperplasia to squamous metaplasia. The incidence and severity of squamous metaplasia increased with concentration. Squamous metaplasia was present in the trachea of almost all male and female mice exposed to 150 and $200 \mathrm{ppm}$ 2,3-hexanedione, and was characterized by focal 
to focally extensive areas of elongate flattened squamous epithelium that replaced the normal respiratory epithelium (Figure 5A, B). The squamous metaplasia frequently was contiguous with zones of epithelial regeneration, atrophy, or hyperplasia. Chronic active inflammation, usually minimal to mild, was present in most exposed mice. Degenerative epithelial changes also were noted in most exposed males and females (Figure 5C), and were characterized by foci of cytoplasmic or intercellular vacuolation (or both), often with scattered apoptotic bodies, and sometimes accompanied by granular degeneration of the basal portion of the epithelium. The vacuolation was often microvacuolar, viewed best with a $40 \times$ objective. Focal ulceration of the epithelium (Figure 5D) was noted in three of the $150 \mathrm{ppm}$ males, and in one each of the $100 \mathrm{ppm}$ and 200 ppm male mice, but was not observed in female mice. Epithelial atypia was sometimes present and was characterized by karyomegaly, hyperchromasia, variation in nuclear size and shape, and usually an increased nuclear-to-cytoplasmic ratio.

Table 3. Laryngeal and Tracheal Lesions in Mice Exposed to 2,3-Hexanedione

\begin{tabular}{|c|c|c|c|c|}
\hline & 0 ppm & 100 ppm & 150 ppm & 200 ppm \\
\hline \multicolumn{5}{|l|}{ Male Mice } \\
\hline \multicolumn{5}{|l|}{ Larynx } \\
\hline Inflammation, chronic active & 0 & $6^{* *}(2.0)$ & $6 * *(2.0)$ & $6^{* *}(1.7)$ \\
\hline \multicolumn{5}{|l|}{ Squamous epithelium } \\
\hline Hyperplasia & 0 & $1(1.0)$ & $1(1.0)$ & $1(1.0)$ \\
\hline \multicolumn{5}{|l|}{ Respiratory epithelium } \\
\hline Hyperplasia & 0 & $1(1.0)$ & $3(1.0)$ & $2(1.5)$ \\
\hline Degeneration & 0 & $4(1.3)$ & $2(1.5)$ & 0 \\
\hline Regeneration & 0 & $1(1.0)$ & $1(1.0)$ & 0 \\
\hline Metaplasia, squamous & 0 & $6^{* *}(2.5)$ & $6^{* *}(3.5)$ & $6^{* *}(2.8)$ \\
\hline \multicolumn{5}{|l|}{ Trachea } \\
\hline Inflammation, chronic active & 0 & $6^{* *}(1.5)$ & $6^{* *}(1.8)$ & $6^{* *}(1.8)$ \\
\hline \multicolumn{5}{|l|}{ Epithelium } \\
\hline Ulcer & 0 & $1(2.0)$ & $3(1.7)$ & $1(1.0)$ \\
\hline Metaplasia, squamous & 0 & $1(2.0)$ & $6^{* *}(1.3)$ & $6^{* *}(2.5)$ \\
\hline Hyperplasia & 0 & $5^{*}(1.0)$ & $4(1.0)$ & $4(2.0)$ \\
\hline Regeneration & 0 & $2(1.5)$ & $4(2.0)$ & $2(1.5)$ \\
\hline Degeneration & 0 & $4(1.3)$ & $6^{* *}(2.2)$ & $5 *(2.5)$ \\
\hline
\end{tabular}

Female Mice

Larynx

Inflammation, chronic active

$0 \quad 6^{* *}(2.0)$

$7^{* *}(2.1)^{\mathrm{c}}$

$6^{* *}(2.0)$

Squamous epithelium

$\begin{array}{lll}\text { Hyperplasia } & 0 & 1(1.0)\end{array}$

Respiratory epithelium 
Respiratory Tract Toxicity of the Flavoring Agent 2,3-Hexanedione in Mice Exposed by Inhalation

\begin{tabular}{lcccc}
\hline & $\mathbf{0 ~} \mathbf{~ p m}$ & $\mathbf{1 0 0} \mathbf{~ p p m}$ & $\mathbf{1 5 0} \mathbf{~ p p m}$ & $\mathbf{2 0 0} \mathbf{~ p p m}$ \\
\hline Metaplasia, squamous & 0 & $5^{*}(2.4)$ & $7^{* *}(3.7)^{\mathrm{c}}$ & $6^{* *}(2.2)$ \\
Hyperplasia & 0 & $2(1.0)$ & $1(1.0)^{\mathrm{c}}$ & $1(2.0)$ \\
Degeneration & 0 & $3(1.7)$ & $4(1.0)^{\mathrm{c}}$ & $1(2.0)$ \\
$\quad$ Regeneration & 0 & 0 & $2(1.5)^{\mathrm{c}}$ & 0 \\
$\begin{array}{l}\text { Trachea } \\
\text { Inflammation, chronic active }\end{array}$ & 0 & $5^{*}(2.0)$ & $7^{* *}(2.1)^{\mathrm{c}}$ & $6^{* *}(1.8)$ \\
Epithelium & & & & \\
$\quad$ Ulcer & 0 & 0 & $0^{\mathrm{c}}$ & 0 \\
$\quad$ Metaplasia, squamous & 0 & $3(2.0)$ & $6^{* *}(2.3)^{\mathrm{c}}$ & $6(3.0)^{* *}$ \\
Hyperplasia & 0 & $3(1.0)$ & $3(1.3)^{\mathrm{c}}$ & $4(2.5)$ \\
Regeneration & 0 & 0 & $5^{*}(1.4)^{\mathrm{c}}$ & $1(2.0)$ \\
Degeneration & 0 & $5(1.2)^{*}$ & $7^{* *}(1.9)^{\mathrm{c}}$ & $6^{* *}(1.2)$ \\
\hline
\end{tabular}

Mice were exposed to 2,3-hexanedione vapor 6 hours/day, 5 days/week for 2 weeks.

$* \mathrm{p}<0.05, * * \mathrm{p}<0.01$ significantly increased incidences relative to controls.

${ }^{\mathrm{a} N u m b e r}$ of mice with lesion $(\mathrm{n}=6)$.

${ }^{\mathrm{b}}$ Average severity grade $(1=$ minimal, $2=$ mild, $3=$ moderate, $4=$ marked $)$.

${ }^{c} n=7$ mice per group.

\section{Lung}

Peribronchial inflammation, ranging from minimal to moderate, was noted in all exposed mice (Figure 6A, B). Inflammation consisted predominantly of lymphocytes and mononuclear cells, with fewer neutrophils, and in most animals extended linearly to some smaller bronchial branches (Table 4). Because of the linear distribution of the infiltrates, the lack of follicle formation, and coexistence of alterations of the bronchial epithelium, the infiltrates were deemed inflammatory rather than just inducible BALT (bronchus associated lymphoid tissue).

Hyperplasia of the bronchial epithelium, noted primarily in the large bronchi, was present in most exposed mice. Hyperplasia was minimal to mild in most cases, and presented as a slightly thickened respiratory epithelium with nuclear crowding and scattered mitotic figures and nuclei often noted in the upper portion of the epithelium (Figure 6A, B). In addition, all $200 \mathrm{ppm}$ males and females exhibited areas of prominent nuclear enlargement, hyperchromasia, and variation in nuclear size and shape of the bronchial epithelium; these areas were termed atypical hyperplasia (Figure 6C). A few of the 150 and $200 \mathrm{ppm}$ mice showed foci of squamous metaplasia or regeneration of the epithelium (Figure 6D).

Table 4. Bronchial Lesions in Mice Exposed to 2,3-Hexanedione

\begin{tabular}{lcccc}
\hline & $\mathbf{0 ~ p p m}$ & $\mathbf{1 0 0} \mathbf{~ p p m}$ & $\mathbf{1 5 0} \mathbf{~ p p m}$ & $\mathbf{2 0 0} \mathbf{~ p p m}$ \\
\hline Male Mice & & & & \\
\hline $\begin{array}{l}\text { Inflammation, chronic active } \\
\text { Respiratory epithelium } \\
\quad \text { Hyperplasia, atypical }\end{array}$ & 0 & $6^{* * a}(1.5)^{\mathrm{b}}$ & $6^{* *}(2.3)$ & $6^{* *}(2.7)$ \\
\hline
\end{tabular}


Respiratory Tract Toxicity of the Flavoring Agent 2,3-Hexanedione in Mice Exposed by Inhalation

\begin{tabular}{lcccc}
\hline & $\mathbf{0 ~} \mathbf{~ p m}$ & $\mathbf{1 0 0} \mathbf{~ p p m}$ & $\mathbf{1 5 0} \mathbf{~ p p m}$ & $\mathbf{2 0 0} \mathbf{~ p p m}$ \\
\hline Hyperplasia & 0 & $5^{*}(1.0)$ & $6^{* *}(1.8)$ & $6^{* *}(2.2)$ \\
Metaplasia squamous & 0 & 0 & $2(1.5)$ & 0 \\
Regeneration & 0 & 0 & $1(1.0)$ & $4(1.3)$ \\
$\quad$ Degeneration & 0 & $3(1.0)$ & $5^{*}(1.6)$ & $6^{* *}(1.8)$ \\
\hline Female Mice & & & \\
\hline Inflammation, chronic active & 0 & $6^{* *}(1.8)$ & $7^{* *}(2.0)^{\mathrm{c}}$ & $6^{* *}(2.2)$ \\
Respiratory epithelium & 0 & & & \\
$\quad$ Hyperplasia, atypical & 0 & 0 & $2(1.0)^{\mathrm{c}}$ & $6^{* *}(1.8)$ \\
$\quad$ Hyperplasia & 0 & $6^{* *}(1.0)$ & $7^{* *}(1.3)^{\mathrm{c}}$ & $6^{* *}(1.7)$ \\
$\quad$ Metaplasia, squamous & 0 & 0 & $1(2.0)^{\mathrm{c}}$ & $1(1.0)$ \\
Regeneration & 0 & 0 & $2(1.0)^{\mathrm{c}}$ & $3(1.3)$ \\
Degeneration & & $1(1.0)$ & $6^{* *}(1.3)^{\mathrm{c}}$ & $6^{* *}(1.8)$ \\
\hline
\end{tabular}

Mice were exposed to 2,3-hexanedione vapor 6 hours/day, 5 days/week for 2 weeks.

$* \mathrm{p}<0.05, * * \mathrm{p}<0.01$ significantly increased incidences relative to controls.

${ }^{\text {aNumber }}$ of mice with lesion ( $n=6 /$ group $)$.

${ }^{\mathrm{b}}$ Average severity grade $(1=$ minimal, $2=$ mild, $3=$ moderate, $4=$ marked $)$.

${ }^{c} \mathrm{n}=7$ mice per group.

Squamous metaplasia was characterized by replacement of the normal respiratory epithelium with a multilayered epithelium of squamoid cells having a flattened cell layer at the surface. Epithelial regeneration was noted in focal areas of the bronchial epithelium, presenting as a single layer of elongate squamoid epithelial cells that stretched to cover the bronchial surface, usually at points of bronchial bifurcation (Figure 6E). A somewhat subtle degenerative epithelial change, manifested by cytoplasmic or intercellular vacuolation (or both), often was noted in the 150 and 200 ppm groups, and occasionally in the 100 ppm groups (Figure 6E, F). Slight karyomegaly and cytoplasmic hypertrophy were noted in bronchiolar epithelium of a few treated animals. 
Respiratory Tract Toxicity of the Flavoring Agent 2,3-Hexanedione in Mice Exposed by Inhalation

\section{Discussion}

The results of this study indicate that 2,3-hexanedione vapor is considerably less toxic to the respiratory tract of mice than 2,3-butanedione, based on a previous study ${ }^{13}$ that reported moribundity in most of the C57BL/6 mice exposed to $200 \mathrm{ppm}$ of 2,3-butanedione for 6 hours a day for 5 days. This study's results in mice support a similar finding in rats exposed to the same 2,3-hexanedione vapor concentrations ${ }^{10}$. Although 2,3-hexanedione was less toxic than 2,3-butanedione or 2,3-pentanedione in rats and did not cause obliterative bronchiolitis, inhalation of 2,3-hexanedione vapor still caused significant toxicity for the respiratory tract of mice. Squamous metaplasia of the respiratory epithelium was the most prevalent lesion in 2,3-hexanedione-exposed mice and was present in the nose, larynx, and trachea of almost all animals. Squamous metaplasia is a common lesion caused by inhaled irritants and is an adaptive response to repeated injury of the epithelium lining the respiratory $\operatorname{tract}^{14 ; 15}$. Inhalation of directacting irritants like 2,3-hexanedione, 2,3-butanedione, and 2,3-pentanedione causes a characteristic sequence of events, beginning with injury to the epithelium lining the upper respiratory tract.

In rodents, the nose is the only portal of entry for inhaled chemicals because rodents are obligate nose breathers; thus, the rodent nasal cavity is exposed to the highest concentrations of inhaled vapors and is often the site of the most severe toxicity from volatile direct-acting chemicals. Squamous metaplasia of the respiratory epithelium was the most prevalent nasal lesion in 2,3-hexanedione-exposed mice, and was present in almost all animals. 2,3-Hexanedione caused a similar incidence and severity (mild to moderate) of squamous metaplasia of nasal respiratory epithelium in rats ${ }^{10}$.

2,3-Hexanedione vapors also caused turbinate atrophy in the nasal cavity of many male and some female mice. Atrophy of the turbinates can occur after exposure to highly irritating agents and is most commonly seen in chronic inhalation studies. It is typically accompanied or preceded by epithelial lesions, such as necrosis or inflammation. The pathogenesis of turbinate atrophy is unclear, but cytokines released by epithelial cells, inflammatory cells, or both during chronic inflammation have been hypothesized to shift the balance between bone resorption and new bone production toward osteoclastic activity (and perhaps decreased osteoblastic activity), resulting in a net loss of bone ${ }^{16}$. Although present in 2,3-hexanedione-exposed mice, turbinate atrophy was not observed in male rats exposed to the same concentrations of 2,3-hexanedione for 2 weeks ${ }^{10}$. These species differences in nasal lesions might be due to differences in respiration, regional disposition of inhaled vapors, or tissue susceptibility.

Squamous metaplasia was also the most prevalent lesion in the larynx and trachea of 2,3-hexanedione-exposed mice. Squamous metaplasia was reported as more severe in the larynx than in the nasal cavity of 2,3-hexanedione, 2,3-butanedione, or 2,3-pentanedione-exposed rats ${ }^{10}$. Although the nasal cavity is exposed to higher 2,3-hexanedione concentrations than the larynx, the nasal epithelium might be less susceptible to injury from inhaled irritants because it is partially protected by a mucous layer. In the trachea, squamous metaplasia was considerably more prevalent in mice than in rats exposed to $150 \mathrm{ppm}$ 2,3-hexanedione, suggesting a potential species difference in susceptibility. Vacuolar degenerative epithelial changes noted in the respiratory tract, particularly in the trachea and bronchi, often appeared to be intracytoplasmic, 
but also might have been intercellular, similar to the basal/suprabasal spongiotic changes described in in vitro epithelial tissues exposed to diacetyl vapors ${ }^{17}$.

Intrapulmonary tissues are partially protected from reactive toxicants because a large amount of chemical is scrubbed from the inhaled air by absorption and reaction in the upper respiratory tract. When exposure concentrations overwhelm the scrubbing capacity of the upper respiratory tract, however, toxic concentrations of chemical can reach the distal airways. Because 2,3-hexanedione is less water soluble and less reactive than 2,3-butanedione and 2,3-pentanedione, that 2,3-hexanedione could penetrate to more distal regions of the respiratory tract and cause greater toxicity in the deeper lung was of concern. The most significant lesion in the bronchi of 2,3-hexanedione-exposed mice was atypical hyperplasia. Atypical hyperplasia of the bronchial epithelium was present in all mice exposed to $200 \mathrm{ppm}$ 2,3-hexanedione. Hyperplasia of the bronchial epithelium was also present in almost all 2,3-hexanedione-exposed mice. The biological significance of cellular atypia is unknown; although atypia could represent a preneoplastic change, particularly when associated with epithelial hyperplasia or squamous metaplasia $^{16}$, focal regeneration of bronchial epithelium was noted in a few mice in the 150 and 200 ppm groups, suggesting that the atypical cytological changes could be related to regenerative changes following previous injury. Atypical epithelial hyperplasia was not observed in rats exposed to 2,3-hexanedione, although the prevalence of bronchial epithelium hyperplasia increased with exposure concentration and was present in all rats exposed to $200 \mathrm{ppm}$ 2,3-hexanedione ${ }^{12}$.

The presence of bronchial epithelial hyperplasia and atypical hyperplasia in exposed mice indicates that a toxic concentration of 2,3-hexanedione reached the airways; however, 2,3-hexanedione did not cause airway fibrosis or obliterative bronchiolitis-like lesions. In rats, 2,3-hexanedione caused only focal areas of minimal bronchial fibrosis in two animals, and unlike 2,3-butanedione and 2,3-pentanedione, 2,3-hexanedione did not cause obliterative bronchiolitislike lesions ${ }^{10}$. Repeated loss of airway epithelium and disruption of the basement membrane might be necessary for fibrosis to develop. 
Respiratory Tract Toxicity of the Flavoring Agent 2,3-Hexanedione in Mice Exposed by Inhalation

\section{Conclusions}

2,3-Hexanedione caused a variety of lesions in the nose, larynx, trachea, and bronchi, including nasal turbinate atrophy and necrosis, tracheal and laryngeal squamous metaplasia, and atypical hyperplasia of bronchial epithelium in $\mathrm{B} 6 \mathrm{C} 3 \mathrm{~F} 1$ mice. Inhaled 2,3-hexanedione vapor targeted the same sites in the respiratory tract as 2,3-butanedione and 2,3-pentanedione. Importantly, 2,3-hexanedione did not cause airway fibrosis or obliterative bronchiolitis-like lesions in mice. Although less toxic than 2,3-butanedione (based on previously reported exposure of C57BL/6 mice to 2,3-butanedione ${ }^{13}$ ), 2,3-hexanedione caused respiratory tract irritation and epithelial lesions in mice. 
Respiratory Tract Toxicity of the Flavoring Agent 2,3-Hexanedione in Mice Exposed by Inhalation

\section{References}

1. Zviely M. Molecule of the month: 2,3-Pentanedione. Perfumer \& Flavorist. 2009; 34:20.

2. Etter J-F, Zather E, Svennson S. Analysis of refil liquids for electronic cigarettes. Addiction. 2013; 108:1671-1679. http://dx.doi.org/10.1111/add.12235

3. Farsalinos KE, Kistler KA, Gilman G, Voudris V. Evaluation of electronic cigarette liquids and aerosol for the presence of selected inhalation toxins. Nicotine \& Tob Res. 2014; 17(2):168174. http://dx.doi.org/10.1093/ntr/ntu176

4. Al Rashidi M, Shihadeh A, Saliba NA. Volatile aldehydes in the mainstream smoke of the narghile waterpipe. Food Chem Tox. 2008; 46:3546-3549.

http://dx.doi.org/10.1016/j.fct.2008.09.007

5. Shihadeh A, Salman R, Jaroudi E, Saliba NA, Sepetdjian E, M.D. B, Cobb CO, Eissenberg T. Does switching to a tobacco-free waterpipe product reduce toxicant intake? A crossover study comparing CO, NO, PAH, volatile aldehydes, tar, and nicotine yields. Food Chem Tox. 2012; 50:1494-1498. http://dx.doi.org/10.1016/j.fct.2012.02.041

6. Kreiss K, Gomaa A, Kullman G, Fedan K, Simoes EJ, Enright PL. Clinical bronchiolitis obliterans in workers at a microwave-popcorn plant. N Engl J Med. 2002; 347(5):330-338. http://dx.doi.org/10.1056/NEJMoa020300

7. Van Rooy GB, Rooyackers JM, Prokop M, Houba R, Smit LAM, Heedrik DJJ. Bronchiolitis obliterans syndrome in chemical workers producing diacetyl for food flavorings. Am J Respir Crit Care Med. 2007; 176:498-504. http://dx.doi.org/10.1164/rccm.200611-16200C

8. Morgan DL, Jokinen MP, Johnson CL, Gwinn WM, Price HC, Flake GP. Bronchial fibrosis in rats exposed to 2,3-butanedione and 2,3-pentanedione. Toxicologist. 2012; 126(1):866.

9. Day G, LeBouf R, Grote A, Pendergrass S, Cummings K, Kreiss K, Kullman G. Identification and measurement of diacetyl substitutes in dry bakery mix production. J Occup Environ Hyg.

2011; 8(2):93-103. http://dx.doi.org/10.1080/15459624.2011.547148

10. Morgan DL, Jokinen MP, Johnson CL, Price HC, Gwinn WM, Bousquet RW, Flake GP. Chemical reactivity and respiratory toxicity of the $\alpha$-diketone flavoring agents: 2,3-butanedione, 2,3-pentanedione, and 2,3-hexanedione. Toxicol Pathol. 2016; 44(5):763-783.

http://dx.doi.org/10.1177/0192623316638962

11. Hallagan JB. The use of diacetyl (2,3-butanedione) and related flavoring substances as flavorings added to foods-workplace safety issues. Toxicology. 2017; 388:1-6.

http://dx.doi.org/10.1016/j.tox.2017.05.010

12. Gavin CL, Williams MC, Hallagan JB. Poundage and technical effects update survey.

Washington, DC: Flavor and Extract Manufacturers Association of America; 2008.

13. Morgan DL, Flake GP, Kirby PJ, Palmer SM. Respiratory toxicity of diacetyl in C57Bl/6 mice. Toxi Sci. 2008; 103(1):169-180. http://dx.doi.org/10.1093/toxsci/kfn016 
14. Herbert RA, Leininger JR. Nose. Larynx and Trachea In: Maronpot RR, editor. Pathology of the Mouse. Vienna, IL: Cache River Press; 1991. p. 235-258.

15. Haschek WM, Rousseaux CG, Wallig MA. Respiratory System In: Haschek WM, Rousseaux CG, Wallig MA, editors. Fundamentals of Toxicologic Pathology. New York, NY: Academic Press; 2010. p. 93-133. http://dx.doi.org/10.1016/B978-0-12-370469-6.00006-4

16. National Toxicology Program (NTP). Nonneoplastic Lesion Atlas. 2017. https://ntp.niehs.nih.gov/nnl/respiratory/lung/metapsqu/index.htm [Accessed: September 26, 2017]

17. Gwinn WM, Flake GP, Bousquet RW, Taylor GJ, Morgan DL. Airway injury in an in vitro human epithelium-fibroblast model of diacetyl vapor exposure: diacetyl-induced basal/suprabasal spongiosis. Inhal Toxicol. 2017; 29(7):310-321. http://dx.doi.org/10.1080/08958378.2017.1369604 

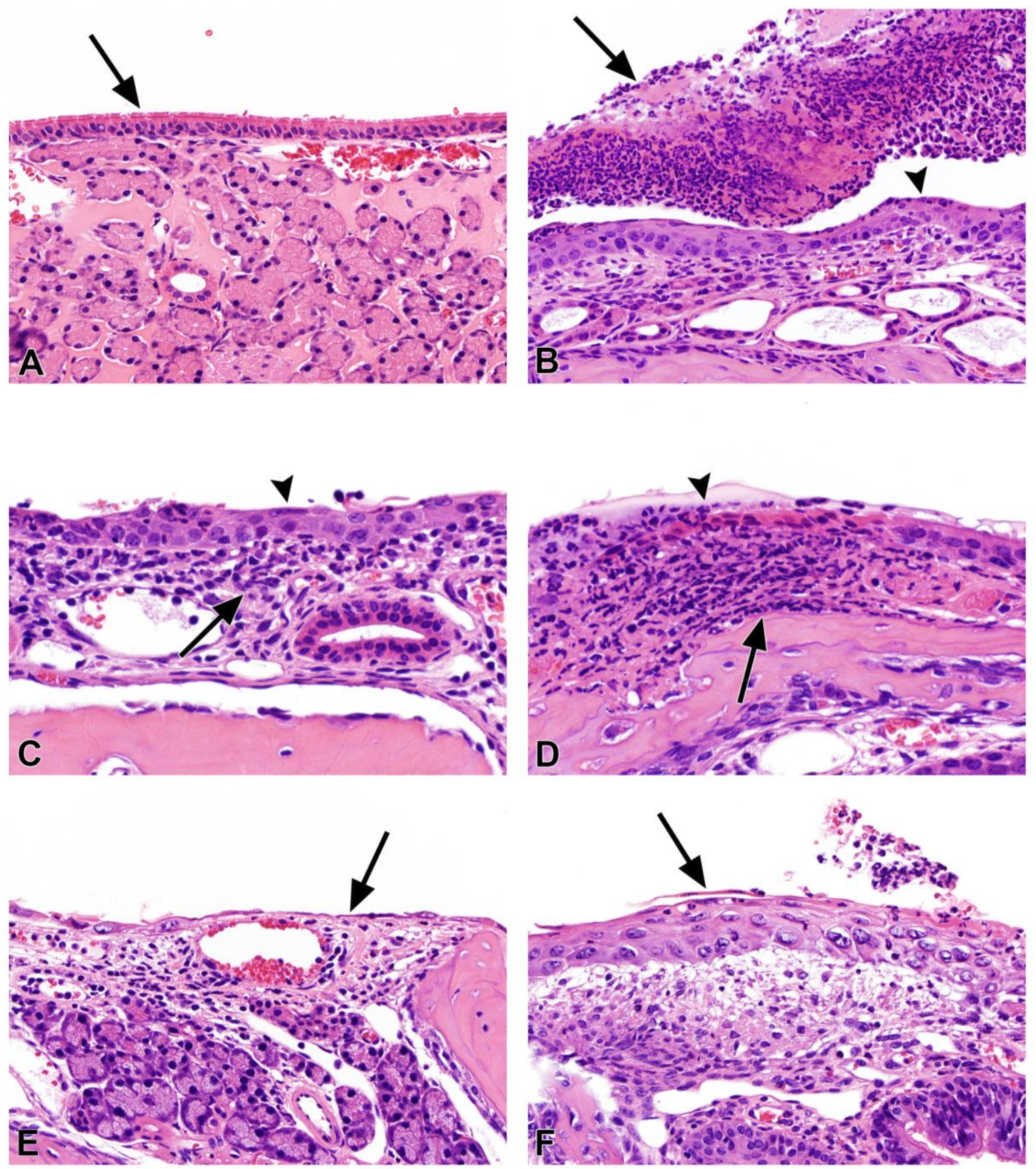

Figure 1. Nose: Respiratory Epithelial Lesions

A) Normal columnar, ciliated respiratory epithelium (arrow). 0 ppm male; original magnification: 40×; H\&E.

B) Suppurative exudate (arrow) in nasal cavity, and replacement of respiratory epithelium by squamous metaplastic epithelium (arrowhead). 150 ppm female; original magnification: 40x; H\&E.

C) Chronic active inflammation (arrow) of nasal mucosa, with overlying squamous metaplasia (arrowhead). $150 \mathrm{ppm}$ female; original magnification: $60 \times ; H \& E$.

D) Respiratory epithelial necrosis (arrowhead), characterized by nuclear pyknosis and cytoplasmic eosinophilia, and accompanied by inflammatory infiltrate (arrow). 200 ppm female; original magnification: 60x; H\&E.

E) Regeneration of respiratory epithelium (arrow). The surface is covered by a single layer of flattened epithelial cells, which have stretched to cover an eroded respiratory epithelium. 200 ppm female; original magnification: 40x; H\&E.

F) Squamous metaplasia (arrow) has replaced the respiratory epithelium. Squamous metaplastic epithelium is more resistant to injury from toxins but lacks the mucous production and ciliary action of respiratory epithelium. $200 \mathrm{ppm}$ female; original magnification: 40x; H\&E. 

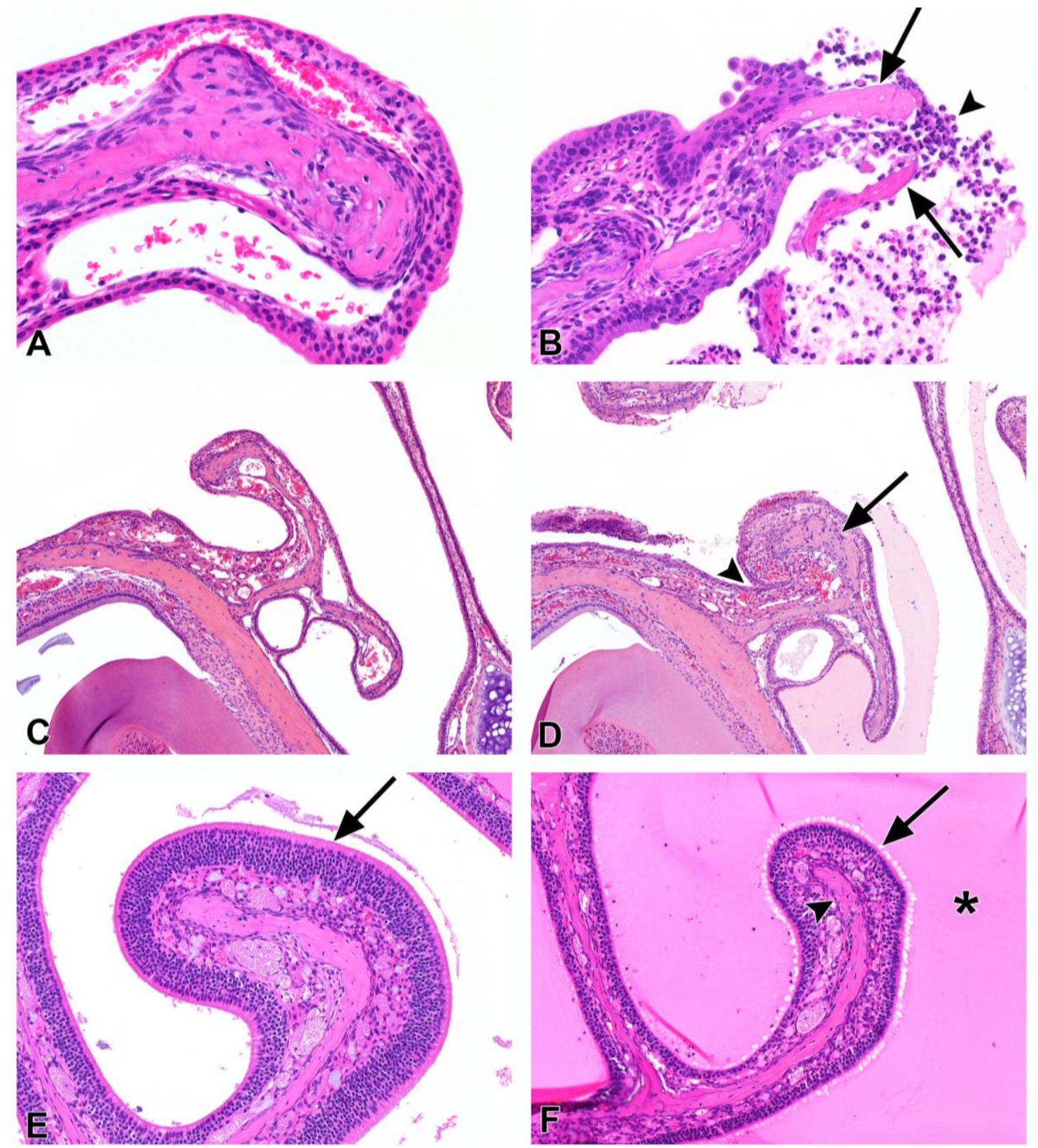

Figure 2. Nose: Turbinate and Olfactory Epithelial Lesions

A) Normal maxilloturbinate, Level I. 0 ppm female; original magnification: 20x; H\&E.

B) Maxilloturbinate, with bone necrosis (arrows), Level I. The bone is attenuated, lacks osteocytes, and is being extruded into the nasal lumen. An associated acute inflammatory reaction (arrowhead) is present. 200 ppm female; original magnification: 20×; H\&E.

C) Normal maxilloturbinate, Level I. 0 ppm female; original magnification: 10x; H\&E.

D) Maxilloturbinate with atrophy, Level I. The bone of the dorsal half of the turbinate (arrow) is thickened but shortened, the stroma is thickened, and the dorsal half of the turbinate has formed a synechia (arrowhead) with the base of the turbinate. $150 \mathrm{ppm}$ male; original magnification: 10x; H\&E.

E) Normal ethmoid turbinate, Level III, with thick, multinuclear layered olfactory epithelium (arrow). 0 ppm female; original magnification: 10x; H\&E.

F) Ethmoid turbinate, Level III, with atrophy of olfactory epithelium (arrow) and turbinate bone (arrowhead). Compare epithelium and bone in $\mathrm{F}$ to the normal turbinate in $\mathrm{E}$. The proteinaceous fluid (asterisk) filling the nasal lumen could be responsible for the turbinate atrophy as a result of pressure effect. 200 ppm female; original magnification: 10x; H\&E. 


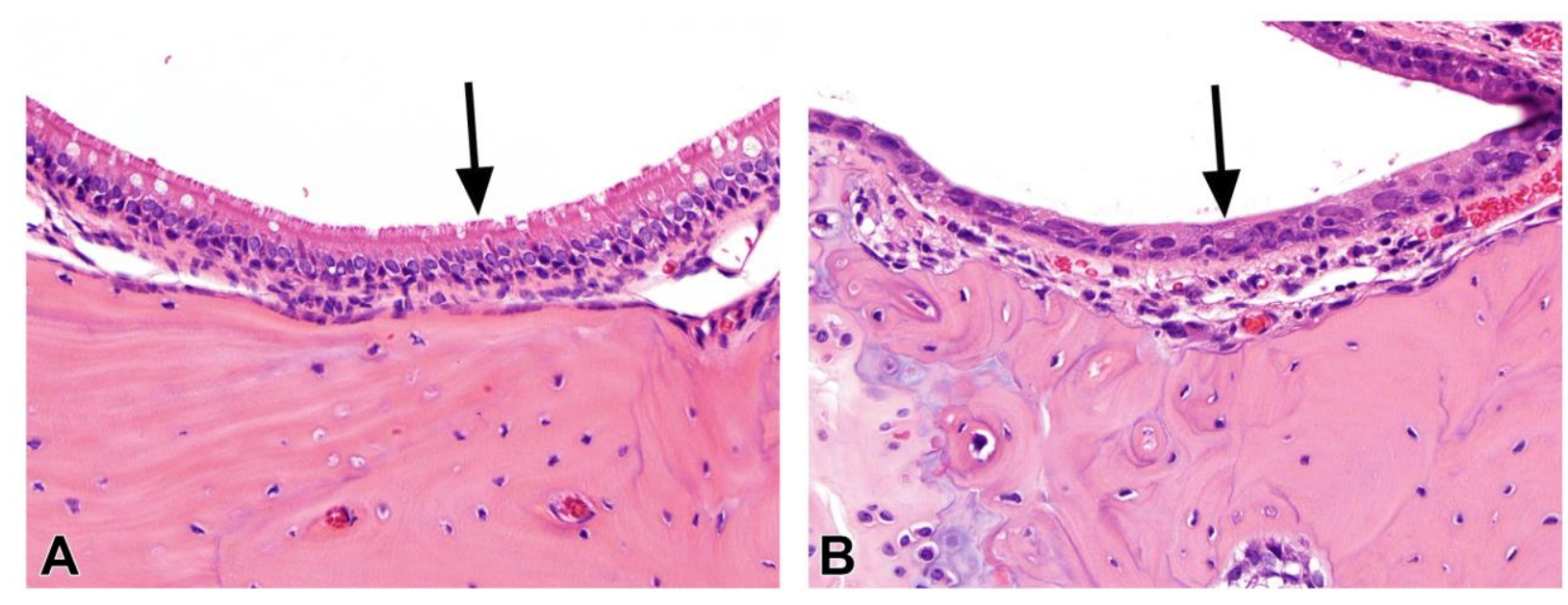

Figure 3. Nasopharyngeal Duct: Squamous Metaplasia

A) Normal respiratory epithelium (arrow) of nasopharyngeal duct. 0 ppm male; original magnification: 40x; H\&E.

B) Squamous metaplastic epithelium (arrow) replacing the respiratory epithelium. $200 \mathrm{ppm}$ female; original magnification: 40x; H\&E. 

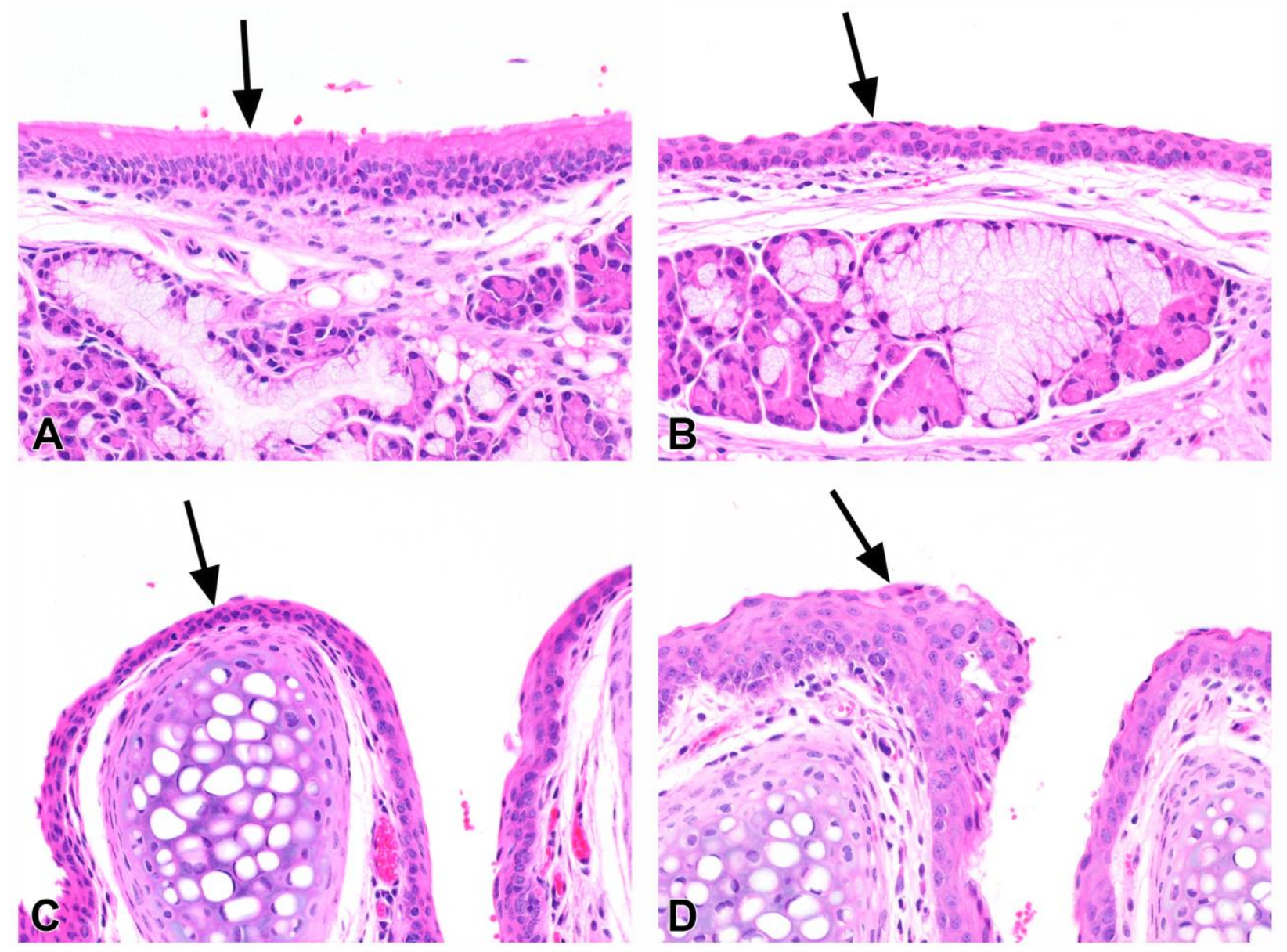

Figure 4. Larynx: Squamous Metaplasia and Squamous Hyperplasia

A) Normal respiratory epithelium (arrow) of base of epiglottis. 0 ppm female; original magnification: 20×; H\&E.

B) Squamous metaplastic epithelium (arrow) replacing respiratory epithelium of the base of epiglottis. 200 ppm male; original magnification: 20x; H\&E.

C) Normal squamous epithelium (arrow) overlying arytenoid cartilage of Level I. 0 ppm male; original magnification: 20×; H\&E.

D) Squamous epithelial hyperplasia (arrow) overlying arytenoid cartilage of Level I. 200 ppm male; original magnification: 20x; H\&E. 

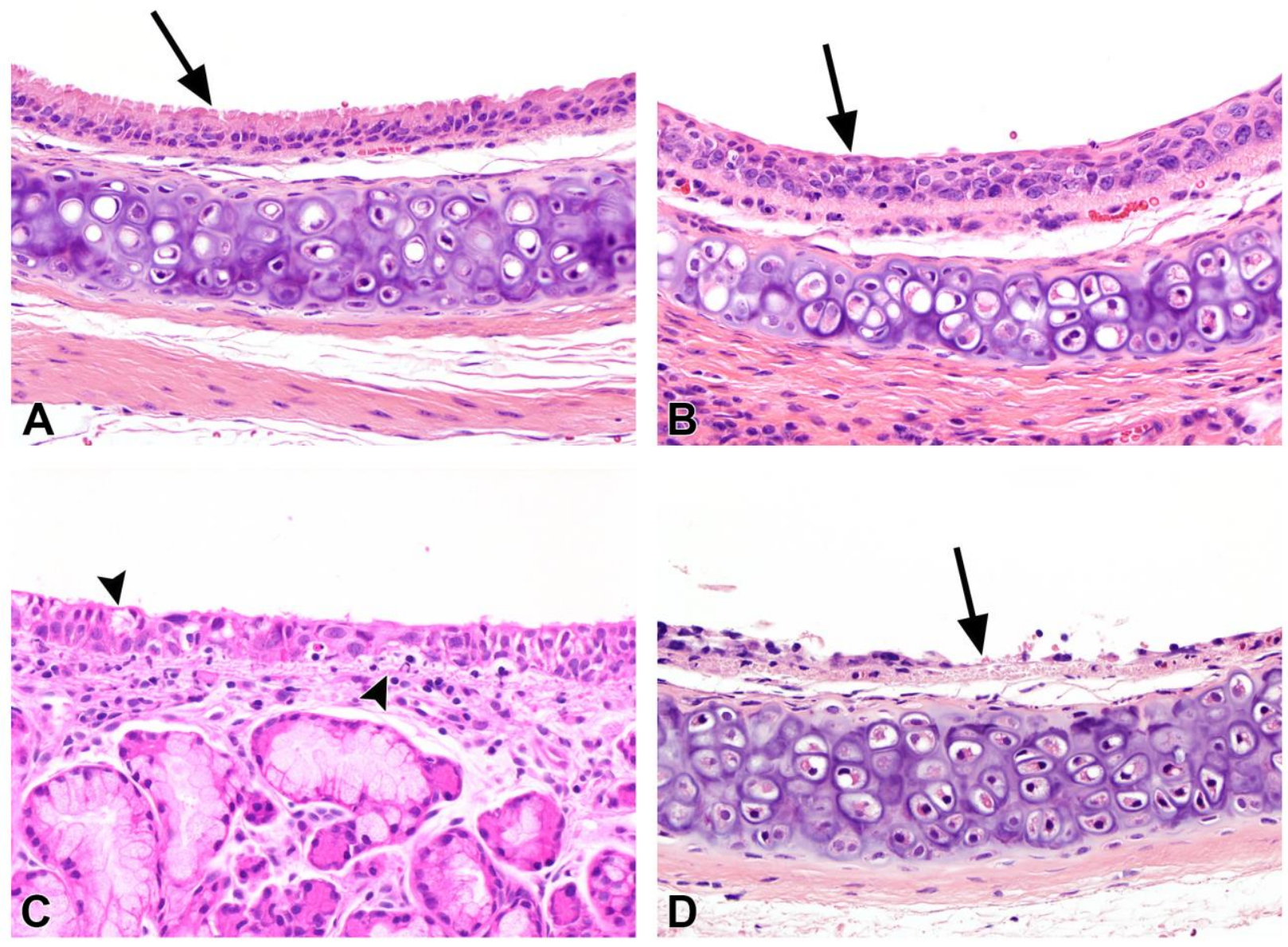

Figure 5. Trachea: Squamous Metaplasia, Degeneration, and Ulceration

A) Normal respiratory epithelium (arrow) of trachea. 0 ppm female; original magnification: 40x; H\&E.

B) Squamous metaplastic epithelium (arrow) replacing the respiratory epithelium. $200 \mathrm{ppm}$ male; original magnification: 40×; H\&E.

C) Vacuolar degeneration (arrowheads) of epithelium and base of epithelium. 200 ppm male; original magnification: 20×; H\&E.

D) Ulcer (arrow) of epithelium, leaving a denuded surface except for a few basal cells and regenerating cells. $150 \mathrm{ppm}$ male; original magnification: $40 \times$; HE. 

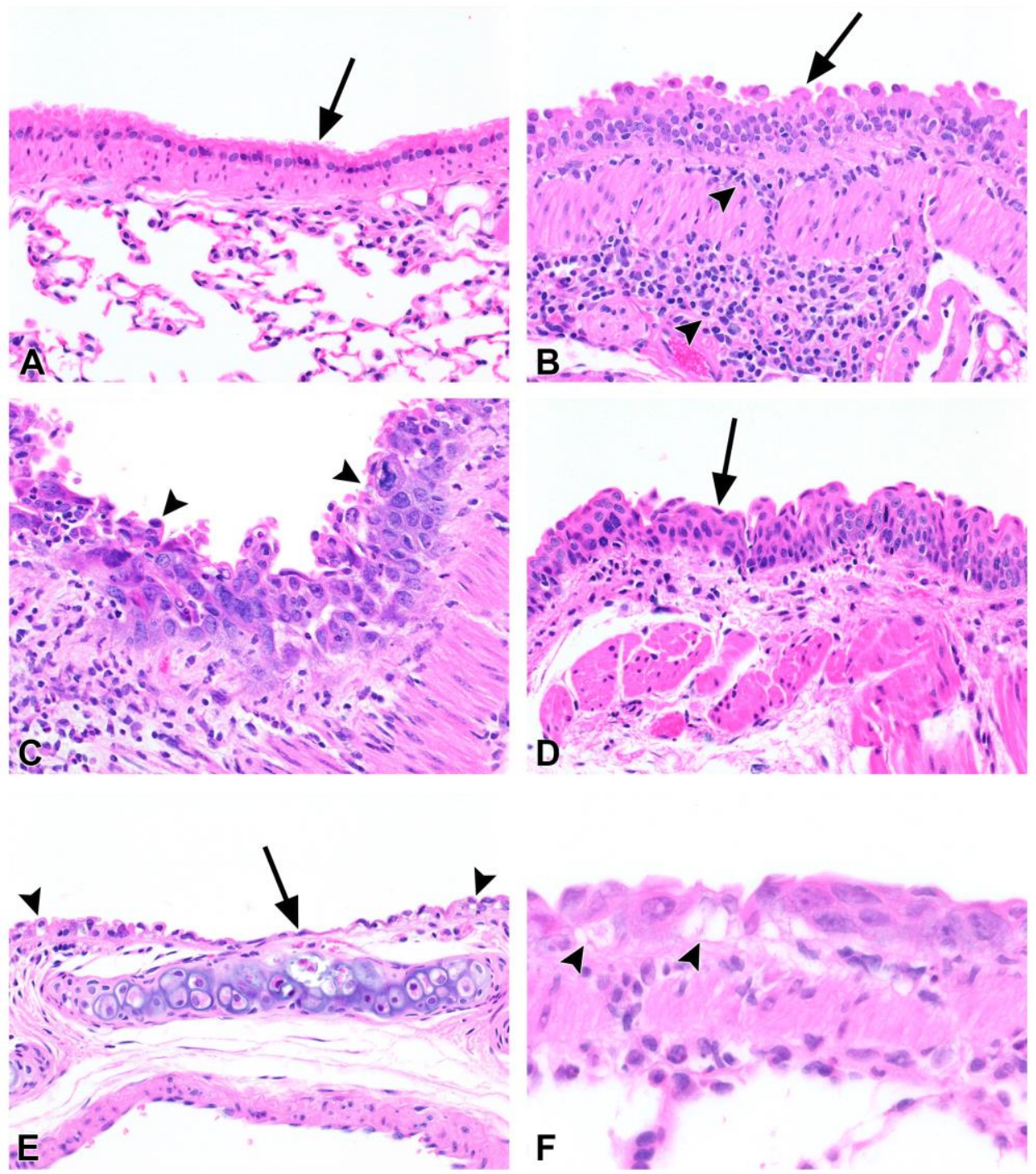

Figure 6. Lung, Bronchus: Respiratory Epithelial Lesions

A) Normal columnar, ciliated respiratory epithelium (arrow) of bronchus. 0 ppm male; original magnification: 20x; H\&E.

B) Epithelial hyperplasia (arrow) of bronchus and chronic active inflammation (arrowheads). $150 \mathrm{ppm}$ male; original magnification: 20x; H\&E.

C) Atypical epithelial hyperplasia (arrowheads) of bronchus, characterized by nuclear enlargement and hyperchromasia, pleomorphism, and disordered arrangement. 200 ppm female; original magnification: 20x; H\&E.

D) Squamous metaplasia (arrow) of bronchial epithelium. 150 ppm female; original magnification: 20x; H\&E.

E) Regeneration (arrow) of bronchial epithelium, characterized by a single flattened layer, and indicative of regenerative response to previous erosion. Note vacuolar degenerative changes (arrowheads) of adjacent epithelium. $200 \mathrm{ppm}$ female; original magnification: 20x; H\&E.

F) Vacuolar degeneration (arrowheads) of reactive metaplastic squamoid epithelium of bronchus. 200 ppm male; original magnification: 40×; H\&E. 


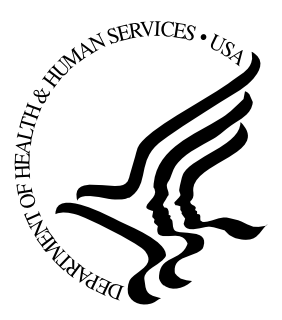

\section{National Toxicology Program}

\section{NTP Central Data Management, MD K2-05}

National Institute of Environmental Health Sciences

P.O. Box 12233

Research Triangle Park, NC 27709

http://ntp.niehs.nih.gov 